\title{
REVIEW
}

\section{HEIDI JENSEN}

\section{ANTROPOLOGI I BØRNELAND? \\ OM „BØRNEANTROPOLOGI“ OG „BØRNEKULTUR“}

VERED AMIT-TALAI AND HELENA WULFF (red.): Youth Cultures: A Cross-Cultural Perspective. London and New York: Routledge 1995. 239 sider. ISBN 0-415-109841. Pris $£ 14,99(\mathrm{pb})$.

ALLISON JAMES, CHRIS JENKS AND ALAN PROUT: Theorizing Childhood. Cambridge: Polity Press 1998. 247 sider. ISBN 0-7456-1564-3. Pris $£ 45$ (hb). ISBN 07456-1565-1. Pris: $£ 13,95$ (pb).

SHARON STEPHENS (red.): Children and the Politics of Culture. Princeton Studies in Culture/Power/History. Princeton, New Jersey: Princeton University Press 1995. 366 sider. ISBN 0-691-04329-9. Pris: \$ 55 (hb). ISBN 0-691-04328-0. Pris: \$ 17,95 (pb).

Folkemindesamleren og antropologen kan, uden at bevæge sig en mil fra sin hoveddør, undersøge en blomstrende og meget lidt selvbevidst kultur (ordet kultur bruges her med velberåd hu), som den sofistikerede verden bemærker lige så lidt, og som påvirkes lige så lidt af denne, som hvis der var tale om en reduceret indfødt stamme i sin hjælpeløse eksistens i udkanten af et indianerreservat (Opie \& Opie 1955:1-2). ${ }^{1}$

Da Charlotte Hardman i starten af 1970'erne spurgte: „Kan man forestille sig en antropologisk retning, som beskæftiger sig med børn?", lod hun sig inspirere af Iona og Peter Opie (Hardman 1973). På baggrund af deres mangeårige studier af engelske børns brug af sange, rim og remser og deres måde at tale sammen med jævnaldrende, konkluderede de, at der eksisterer en særskilt og varig børnekultur (Opie \& Opie 1955). Hardman stod dengang ret alene med sin vision om en børneantropologi, der skulle betragte børn som mennesker, der fortjener at blive studeret ,i egen ret“. Hendes ambition var at unders $\varnothing$ ge, om man gennem studiet af barndom kunne opdage ,en selvregulerende, autonom verden“, som ikke nødvendigvis var et udtryk for en endnu ufærdig udvikling af den voksne kultur (Hardman 1973:87).

Hardmans visioner er i de seneste årtier blevet fremhævet af forskere (f.eks. Prout \& James 1990), som har bidraget til at etablere et felt af antropologisk og sociologisk barndoms- og børneforskning, der er spredt og heterogent, men også voksende både i om- 
fang og gennemslagskraft. ${ }^{2}$ I dag, hvor antropologer hælder til en mere ,distributiv“ tilgang til kultur, ${ }^{3}$ virker Hardmans argument om, at et samfunds eller en kulturs børn tilsammen udgør en kollektiv børnekultur, som derfor kan og bør studeres i sig selv, ikke overbevisende. Det kan diskuteres, hvorvidt børnekulturbegrebet er relevant for nutidige antropologiske analyser af børn og barndom, og det kan være en anledning til at reflektere over, hvad det er, der kendetegner „,børneantropologi“ eller ,,antropologiske studier af børn og barndom", og hvorvidt antropologisk børneforskning kan bruges til andet end at kortlægge eksotiske børnekulturer. Det er disse spørgsmål, jeg vil søge svar på i tre udgivelser, der, hver på sin måde, forsøger at finde pejlemærker for antropologiske og sociologiske studier af og teorier om børn og barndom.

\section{Bøgerne}

Da denne artikel fokuserer på de ovenfor skitserede spørgsmål, vil den ikke kunne give de mange interessante etnografiske bidrag i de to artikelsamlinger, redigeret af henholdsvis Sharon Stephens og Vered Amit-Talai og Helena Wulff (alle antropologer), den opmærksomhed, som de fortjener. Begge udgivelser er i høj grad læseværdige, om end bidragene i Stephens' Children and the Politics of Culture er af en lidt ujævn kvalitet. Dette problem opvejes dog i nogen grad af Stephens' indledning, hvor hun argumenterer særdeles overbevisende for de perspektiver, der ligger i en samlet læsning af artiklerne, hvis fælles tema er de kulturelle, politiske og globale dimensioner af studiet af børn i usikre situationer verden over.

Antropologen Allison James og sociologerne Chris Jenks og Alan Prouts bog er en kompetent gennemgang af især sociologiske og antropologiske barndomsstudier. På baggrund af dette overblik over forskningsfeltet opstiller de en samlet analytisk ramme for en mere teoretisk tilgang til barndom og børn. Denne artikels fokus på den antropologiske relevans af børnekulturbegrebet og af studier af børn og barndom betyder, at der her ikke kan gives en mere uddybende diskussion af forfatternes udforskning af en række forskellige rum, hvor nutidig barndom udspiller sig og studeres. Men det er en bog, som giver læseren et godt overblik over den sociologiske og antropologiske børneforskning og demonstrerer, hvordan denne forskning kan ses som særdeles relevant både $\mathrm{i}$ forhold til videnskabelige og praktiske problemstillinger, og den fortjener at nå en bred læserskare. Det er derfor glædeligt, at der er planer om at udgive den i en dansk oversættelse.

De tre bøger har det til fælles, at de forholder sig til børn som genstandsfelt og diskuterer teoretiske perspektiver af barndomsforskning. Den af Stephens redigerede bog indeholder artikler om børn og unge i en række forskellige etnografiske sammenhænge, der spænder fra kampen mod apartheid i Sydafrika til samekultur i Norge efter Chernobylulykken, men det er kun Stephens' glimrende indledning, som direkte beskæftiger sig med teoretiske perspektiver af det analytiske fokus på barndom og kultur. I den anden artikelsamling, redigeret af Amit-Talai og Wulff, finder man artikler, der bygger på etnografiske studier af børn og unge i Nepal, Canada, England, Salomonøerne, Algeriet og blandt surinamske migranter i Amsterdam. I denne bog behandles emnerne barndom og ungdom teoretisk i Wulffs introduktion, i Amit-Talais konklusion og i to artikler af Virginia Caputo og Allison James. De nævnte bidrag er alle relevante for en diskussion af „,børnekultur“ og ,børneantropologi“. 
Hensigten med James et al.'s bog er, som titlen lægger op til, at teoretisere barndom og derigennem at konsolidere forskningsfeltet, at anvise retninger for forskningen fremover, $\mathrm{og}$ at diskutere forholdet mellem barndomsstudier og antropologisk og sociologisk teori. Hvor James et al. især baserer deres teoretiske argumenter på forskningsresultater fra studier af engelske eller euroamerikanske børn, anlægger de to artikelsamlinger i højere grad et tværkulturelt perspektiv. James et al.'s bog er endvidere mere sociologisk inspireret end artikelsamlingerne. Marilyn Strathern har på glimrende vis redegjort for de forskellige konsekvenser, der er forbundet med at vælge at tage enten et ,sociologisk fikspunkt “ eller et „,kulturelt fikspunkt“ for givet (Strathern 1984). Hvor man med et sociologisk fikspunkt har udgangspunktet, at der eksisterer eksempelvis „sociale klasser“, „,lokalsamfund “ og ,familier", og analysens formål er at anskueliggøre relationerne mellem disse kategorier, betyder valget af et kulturelt fikspunkt, at udgangspunktet bliver menneskers egne repræsentationer og en afvisning af en iboende korrespondance mellem sociale kategorier og sociale grupperinger. Selvom forskellen på antropologisk og sociologisk forskningsstrategi med denne forståelse tydeligvis ikke er et spørgsmål om, hvor dataindsamlingen lokaliseres geografisk, kan man dog sige, at det tværkulturelle perspektiv har været en vigtig forudsætning for udviklingen af antropologisk forskningsstrategi.

De to artikelsamlingers titler, Youth Cultures og Children and the Politics of Culture, antyder, at den første handler om en ældre del af Jordens befolkning end den anden. Det er dog ikke tilfældet, da børnene og de unge, som læseren møder i artiklernes etnografiske cases, i begge udgivelser spænder fra mindre børn i skolealderen til unge mennesker $i$ begyndelsen af tyverne. Dette kan ses som en illustration af én af den antropologiske og sociologiske børneforsknings pointer: at kategorierne barn og ung ikke har en iboende og absolut betydning ud over den, som de tillægges situationelt.

\section{Børnekultur?}

Selv om Stephens' indledning ikke direkte diskuterer børnekulturbegrebets relevans, påpeger hun, at ideen om eksistensen af børnekulturer har spillet en vigtig rolle i bestræbelserne på at sætte fokus på børns handlerum (Stephens 1995:23). Stephens' problematiseren af begrebet begrænser sig til en kritik af den mere universalistiske tilgang til „børnekultur", der opfatter børn som naturligt legende, kreative og spontane og ignorerer de dimensioner af børns liv, som ikke er „for sjov“.

James, Jenks og Prouts bog indeholder et kapitel, der er en diskussion af børnekulturbegrebets epistemologiske status i nutidige barndomsstudier, som jeg vil behandle mere indgående i slutningen af dette afsnit. I dette kapitel redegør James et al. for, hvordan begrebet er blevet anvendt og udviklet i forskellige forskningsmæssige sammenhænge. I den forbindelse påpeger de, at den mere snævre definition af genstandsfeltet for studiet af børnekultur, som Stephens kritiserer, ofte har udmøntet sig i en forskningsmæssig praksis, der dokumenterer og analyserer børns lege og børns ting, sådan som Opie \& Opie gjorde det. Denne tilgang til børnekultur adskiller sig fra den måde, hvorpå begrebet er blevet anvendt af antropologer og sociologer, der har anvendt begrebet til at betegne de dagligdags sammenhænge, som børn indgår i med jævnaldrende (James et al. 1998:82).

I en artikel med titlen „Anthropology's Silent 'Others'“ (i Amit-Talai og Wulffs bog) argumenterer Virginia Caputo for, at antropologer skal interessere sig for børn som hand- 
lende væsener frem for at betragte dem som ufærdige voksne, der kun er blevet delvist kulturelle. I sin iver for at overbevise læseren bruger Caputo flere gange udtryk som „børns kulturer“ og „,børns verdener“ på en måde, der antyder at disse er naturlige og uproblematiske begreber. Eksempelvis læner hun sig op ad børneantropologiske foregangskvinder som Hardman og Suransky, ${ }^{4}$ når hun hævder, at den etnografiske metode er særlig velegnet til at ,give forskere mulighed for at opleve aspekter af børns verdener på tæt hold“ (Caputo 1995:34). Heldigvis finder man en mere konsekvent analytisk forholden sig til begreberne ,børnekultur“ og „,ungdomskultur“ i Amit-Talais konklusion og James' artikel i samme bog.

Flere af bidragene i denne artikelsamling rejser kritik af den måde, hvorpå studier af „ungdomskultur" som subkultur har benyttet modstandsdiskurs som sin teoretiske ramme og som konsekvens heraf har fremstillet selv ,,rebelske“ unges handlinger som reaktioner på en udefrakommende strukturel underordning ${ }^{5}$ frem for at anerkende, at unge kunne være i besiddelse af eget initiativ og handlekraft (Amit-Talai 1995a; Caputo 1995; James 1995; Wulff 1995a, 1995b). Amit-Talai påpeger i sin konklusion, at denne fokusering på subkultur og modstand har betydet, at majoriteten af unge, i modsætning til børn, ikke ses som tilhørende en egen særskilt kultur. De opfattes i stedet enten som på vej til at overtage deres forældres kultur eller som underlagt en multinational og kommerciel ungdomskultur (Amit-Talai 1995a).

James artikel i samme bog sammenholder kritikken af den måde, ungdomskulturbegrebet er blevet brugt, med indsigter fra de nye barndomsstudier. Det giver hende anledning til at foreslå, at „eksisterende forskelle mellem børn og unge menneskers sociale erfaringer og voksnes sådanne“ ikke skal forstås som subkulturer, men som temporale kulturer eller generationelle kulturer (James 1995:46). I artiklen konkluderer James på baggrund af sine etnografiske studier af engelske børn, at „kendskabet til lingvistiske ressourcer og tilegnelsen af performative færdigheder udtrykker børn og unge menneskers relative positioner inden for de generationelle barndoms- og ungdomskulturer" (op.cit.:57), og viser, at udvikling af disse lingvistiske evner er en forudsætning for at mestre bevægelsen fra barndom til ungdom i den engelske sammenhæng.

Frem for at insistere på at tiden og teoriudviklingen i antropologien er løbet fra ideen om „børnekulturer“, og at dette begreb derfor bør opgives, vælger Amit-Talai i lighed med James at underkaste begrebet en kritisk revision, hvor der fokuseres på den processuelle dimension af kultur. I sin konklusion taler Amit-Talai derfor ikke om studier af børnekulturer, men om børn og unges kulturelle produktion. Hun opfordrer antropologer til at undersøge børn og unges virken og medvirken over en bred vifte af steder, hvor denne foregår, og på en måde, som ikke udelukker en medtænken af, hvordan den kulturelle produktion ,trækker på elementer fra både det hjemlige og fra transnationale påvirkninger og er sammenflettet med klasse, køn, etnicitet og lokalitet med al den kulturelle diversitet, som en sådan mangfoldighed af omstændigheder fremtvinger“" (AmitTalai 1995a:231).

James, Jenks og Prouts diskussion af børnekulturbegrebets epistemologiske status går videre med de ideer, som James fremlægger i den ovenfor omtalte artikel. I Theorizing Childhood foreslår de, at begrebets indhold omformuleres, så børnekultur ikke sættes lig med en særskilt livsform, men i stedet ses som en „form for social handlen“ eller, ,en særlig kulturel stil“ (James et al. 1998:90). James et al. peger altså på en tilgang, der interesserer sig for kultur som kontekstualiseret handling, og på, at man med dette 
udgangspunkt kan se børnekultur som tidsmæssigt definerede (midlertidige) rum for kulturel produktion.

Forfatternes analyse af de forskellige måder, hvorpå børnekulturbegrebet er blevet brugt, og deres anvisninger på, hvordan begrebet kan omformuleres, så det er i overensstemmelse med nutidig sociologisk og antropologisk teori, fremstår som både elegant og velargumenteret. Man kan derfor undre sig over, at de i forbifarten noterer sig, at de få studier, der fokuserer på børn i en ikke-europæisk eller nordamerikansk sammenhæng (det specificeres ikke nærmere med referencer eller lignende), ,peger mod, at der i disse sammenhænge ikke findes nogen veludviklet 'børnekultur', da børn og voksnes verdener i disse kontekster er mindre socialt opdelte og kulturelt adskilte" (ibid.). Det forekommer problematisk at fremkomme med så generelle og kategoriske udtalelser om forskellen på børn og barndom i Nord og Syd på et åbenbart smalt grundlag. Hvis studier af børn i Syd viser, at hverken det tidlige eller det reviderede børnekulturbegreb giver mening i den sammenhæng, er det vel en udfordring for den fortsatte udvikling af de samfundsvidenskabelige børne- og barndomsstudiers teorier og begreber, der er værd at tage op.

\section{Har studier af børn antropologisk relevans?}

James et al.'s model (fig. 1) af det teoretiske felt, som de samfundsvidenskabelige studier af barndom udgør, aftegner dette som udspændt mellem fire sociologiske modsætningspar. Det drejer sig om struktur-agens, identitet-forskel, kontinuitet-forandring og lokalglobal, der i modellen anskues i et samspil og ses som udtryk for fire filosofiske retninger, der vægter henholdsvis voluntarisme, determinisme, universalisme og partikularisme. Modellen er samtidig en matrix over fire typer af tilgange, som er fremherskende i nutidig samfundsvidenskabelig barndomsforskning.

\section{VOLUNTARISME AGENS FORSKEL}

Stammebarn

\section{PARTIKULARISME LOKAL FORANDRING}

Minoritetsgruppebarn

UNIVERSALISME GLOBAL KONTINUITET

Socialt struktureret barn

\section{IDENTITET \\ STRUKTUR \\ DETERMINISME}

Fig. 1: Teoretisk felt for det sociale studie af barndom (James et al. 1998:206). 
Selvom det felt, modellen beskriver, er en mangesidig størrelse, mener James et al., at man kan tale om det som ét felt, hvis aktører er fælles om at stå i opposition til de ,transitionelle teorier", der beskæftiger sig med børns sociale udvikling, og dermed fokuserer på, hvad barnet er på vej til at blive og ikke på barnet som person og social aktør i nutidig væren (op.cit.:206-7). Da James et al.'s erklærede formål er at konsolidere og give ny næring til det felt, som deres model skal beskrive, er de mere optagede af, hvordan antropologisk teori og metode kan bruges i dette projekt end i det tema, denne artikel behandler - spørgsmålet om, hvordan studier af børn og barndom er relevante for antropologien. Men det er oplagt, at de spørgsmål og den diskussion af teoretiske kernebegreber, som James et al.'s ramme for samfundsvidenskabelige barndomsstudier lægger op til, i vid udstrækning er sammenfaldende med antropologiske problemstillinger.

De omtalte artikler i de to artikelsamlinger er i forskellig grad optaget af, hvordan analyser af børn kan virke som en udfordring og en inspirationskilde i forhold til centrale, antropologiske, teoretiske og metodiske problemstillinger og i forhold til mere specifikke temaer, som optager antropologer. Hvor Amit-Talai, i en artikel hvor hun præsenterer resultater fra sit feltarbejde blandt canadiske unge i high-school (Amit-Talai 1995b), rejser vigtige spørgsmål for antropologisk analyse af venskab på baggrund af sit etnografiske studie, så viser hendes konklusion i samme bog (Amit-Talai 1995a), at studier af børn og unge er yderst relevante for de bestræbelser, antropologer i de sidste 30 år har gjort sig for at revidere det antropologiske kulturbegreb. Hun bruger bogens artikler som platform for en diskussion, som anviser en vej til at frigøre det antropologiske kulturbegreb fra en identifikation med samfund og kultur, der går videre end bare at lægge et ekstra lag af hybridkultur eller blandede grænseområder oven på de stabile, afgrænsede og homogene kulturelle „øer“. Amit-Talai foreslår, med afsæt i Anthony P. Cohens og Ward H. Goodenoughs teoretiske arbejder, at man anskuer kulturel produktion som lokaliseret i aktiviteter frem for i samfund (jf. Goodenough 1994), medtænker menneskers bevidsthed om deres engagement i mange forskellige, sammensatte situationer eller aktiviteter (jf. Cohen 1994) og kombinerer dette med en opmærksomhed på de rammer, såsom ulige fordeling af viden og magt, der virker bremsende for menneskers handlekraft. Amit-Talai konkluderer: „Unge mennesker er alt andet end 'delvist kulturelle' og har måske en særlig stærk forståelse for den vilkårlige karakter af enhver kulturel erfaring“ (Amit-Talai 1995a:232).

Stephens argumenterer for, at et fokus på barndom er vigtig i forhold til udviklingen af teorier om modernitet og globale processer (Stephens 1995). Hun sammenkæder den spirende antropologiske interesse i børn og barndom med den seneste tids opblomstring af antropologiske studier, der beskæftiger sig med selvet, kroppen, familie- og hverdagsliv. Denne forskning har udfordret opsplitningen mellem politisk økonomi og kultur og det offentlige og det private, som megen videnskabelig tænkning, også verdenssystemteori, opererer med. At rette fokus mod barndom og på børns erfaringer er således en måde, hvorpå man kan udfordre de dominerende modeller for verdenssystemprocesser.

Stephens' diskussion af barndom udmærker sig ved, at de teoretiske overvejelser sættes i relation til aktuelle empiriske problemstillinger, særligt med spørgsmålet om børns rettigheder. Ud over at interessere sig for hvilke teoretiske perspektiver, et antropologisk perspektiv på børn rejser, er Stephens således meget optaget af, hvordan teorierne kan have relevans eller konsekvenser for mere problemorienterede tilgange til børn og barndom. Selvom Stephens overvejende ser positive muligheder i den forbindelse, peger hun 
dog på, at den akademiske tendens til at betragte barndomme som diskursive fænomener, der kun eksisterer inden for deres sociale og historiske sandhedsregimer, kan få utilsigtede konsekvenser og bruges til at afvise eller underminere legitimiteten af synsvinkler og værdier ,som forsøger at modarbejde undertrykkelse af børn, og at børns liv verden over i stigende grad domineres af det internationale markeds værdier (op.cit.:11, fodnote 5).

\section{Børneantropologi?}

De tre udgivelser, der i sig selv er et bevis på, at der er en stigende interesse for genstandsfeltet børn og barndom, er altså fælles om at vise, at studier af børn har relevans for en række antropologiske problemstillinger. Hvor James og hendes kolleger har et stærkt $\emptyset$ nske om at konsolidere de samfundsvidenskabelige barndomsstudier som et tværfagligt felt, der samler sig om en interesse i børn, så fornemmer man, at for Amit-Talai er børn og unge interessante som genstandsfelt på grund af de muligheder, der viser sig i disse studier i forhold til centrale problemer i antropologisk teori og metodologi, og jeg tvivler på, at hun ville acceptere at blive betegnet som „børneantropolog“. Stephens siger direkte, at de udfordringer for samfundsteori, som artiklerne i den bog, hun har redigeret, rejser, er alt for vigtige til at blive isoleret inden for et smalt defineret felt af „børneforskning“ (Stephens 1998:21).

Antropologer, som beskæftiger sig med børn og barndom i deres forskning, står over for et dilemma: For at få gennemslagskraft og opbygge forskningsmæssige netværker kan det synes nødvendigt at etablere sig som en selvstændig disciplin eller retning inden for antropologien, men man løber så samtidig en reel risiko for at blive sat i bås som „børneantropolog ". Som de andre temaer, der, om end overfladisk, berøres i denne artikel, er det ikke en problemstilling, der alene knytter sig til genstandsfeltet børn og barndom. Det afspejler derimod de problemer, som er forbundet med en organisering af det antropologiske forskningsfelt, som fremmer en opsplitning i regionale og tematiske specialiseringer, og som ikke tilskynder den enkelte forsker til at interessere sig for, hvad der sker uden for hendes eget område. ${ }^{6}$ Hvis antropologer, som forsker i og med børn, vil tages alvorligt af den ,voksne“ antropologi, er vejen frem ikke at isolere sig med ligesindede. Men det er klart, at dialogen med andre forskere i barndom kan være vigtig for at udvikle gode argumenter for, hvorfor antropologer i højere grad bør inddrage børn i deres analyser, og for de perspektiver, der ligger i studiet af børn og barndomme i forhold til en lang række af både centrale og mere marginaliserede antropologiske temaer.

\section{Noter}

1. Alle oversættelser til dansk er forfatterens.

2. „De nye samfundsvidenskabelige studier af barndom“ (the new social studies of childhood), som er den betegnelse, James et al. anvender, bedrives ikke kun af antropologer og sociologer, men af forskere fra mange forskellige discipliner såsom psykologi, geografi, jura, historie, filosofi og pædagogik.

3. Barth $(1987,1989)$ og Hannerz (1992) er eksempler på antropologisk forskning, der fokuserer på kultur som distribueret, og på, hvordan viden er ulige fordelt i socialt differentierede befolkninger. 
4. Antropologen Valerie Polakow Suransky udgav i 1982 bogen The Erosion of Childhood. Suransky argumenterer for, at børn er handlende og bevidste personer, som fortjener en større synlighed i den antropologiske forskning.

5. Kritikken retter sig blandt andet mod den såkaldte „Birminghamskole“. forskningsmiljøet omkring Centre for Contemporary Cultural Studies i Birmingham, England, som i 1970'erne og i starten af 1980'erne frembragte en række marxistisk inspirerede analyser af unges subkulturer (f.eks. Hall \& Jefferson 1976; Willis 1977).

6. Judith Okely har med sin videnskabelige produktion leveret et overbevisende argument for værdien af at søge efter indbyrdes forbindelser mellem antropologiske temaer og regioner frem for at indespærre forskning og forskere i snævre regionale eller tematiske områder, der som Okely påpeger, er af en konstrueret karakter, der bygger på tilfældige eller politiske afgrænsninger og udelukkelser (Okely 1996).

\section{Litteratur}

Amit-Talai, Vered

1995a Conclusion: The 'Multi’ Cultural of Youth. I: Amit-Talai \& Wulff (red.): Youth Culture.

A Cross-Cultural Perspective. London: Routledge.

1995b The Waltz of Sociability: Intimacy, Dislocation and Friendship in a Quebec High School. I:

Amit-Talai \& Wulff (red.): Youth Culture. A Cross-Cultural Perspective. London: Routledge.

Barth, Fredrik

1987 Cosmologies in the Making. A Generative Approach to Cultural Variation in Inner New

Guinea. Cambridge Studies in Social Anthropology No. 64. Cambridge: Cambridge

University Press.

1989

The Analysis of Culture in Complex Societies. Ethnos 3-4:120-42.

Caputo, Virginia

1995 Anthropology's Silent 'Others': A Consideration of some Conceptual and Methodological Issues for the Study of Youth and Children's Cultures. I: Amit-Talai \& Wulff (red.):

Youth Culture. A Cross-Cultural Perspective. London: Routledge.

Cohen, Anthony P.

1994 Self Consciousness. An Alternative Anthropology of Identity. London: Routledge.

Goodenough, Ward $\mathrm{H}$.

1994 Towards a Working Theory of Culture. I: R. Borofsky (red.): Assessing Cultural

Anthropology. New York: McGraw-Hill, Inc.

Hall, Stuart \& Tony Jefferson

1976 Resistance through Rituals. Youth Subcultures in Post-War Britain.

London: Hutchinson \& Co.

Hannerz, Ulf

1992 Cultural Complexity: Studies in the Organization of Meaning.

New York: Colombia University Press.

Hardman, Charlotte

1973 Can there be an Anthropology of Children? Journal of the Anthropological Society of Oxford 4(1):85-99.

James, Allison

1995 Talking of Children and Youth: Language, Socialization and Culture. I: Amit-Talai \& Wulff (red.): Youth Culture. A Cross-Cultural Perspective. London: Routledge.

James, Allison, Chris Jenks \& Alan Prout

1998 Theorizing Childhood. Cambridge: Polity Press.

Okely, Judith

1996 Own or Other Culture. London: Routledge. 
Opie, Iona \& Peter Opie

1959 The Lore and Language of Schoolchildren. Oxford: Oxford University Press.

Prout, Alan \& Allison James

1990 A New Paradigm for the Sociology of Childhood? Provenance, Promise and Problems.

I: A. Prout \& A. James (red.): Constructing and Reconstructing Childhood:

Contemporary Issues in the Sociological Study of Childhood. London: The Falmer Press.

Stephens, Sharon

1995 Introduction. Children and the Politics of Culture in 'Late Capitalism'. I: S. Stephens (red.):

Children and the Politics of Culture. Princeton, New Jersey: Princeton University Press.

Strathern, Marilyn

1984 Localism Displaced: A 'Vanishing Village' in Rural England. Ethnos 1-2:43-61.

Suransky, Valerie Polakow

1982 The Erosion of Childhood. Chicago: The University of Chicago Press.

Willis, Paul

1977 Learning to Labour. How Working Class Kids Get Working Class Jobs.

Hampshire: Gower Publishing Company Limited.

Wulff, Helena

1995a Inter-Racial Friendship: Consuming Youth Styles, Ethnicity and Teenage Femininity in South London. I: Amit-Talai \& Wulff (red.): Youth Culture. A Cross-Cultural Perspective. London: Routledge.

1995b Introduction: Introducing Youth Culture in Its Own Right: The State of the Art and New Possibilities. I: Amit-Talai \& Wulff (red.): Youth Culture. A Cross-Cultural Perspective. London: Routledge. 
